\title{
Sebuah Usulan Desain produk: Sandal Kesehatan dengan Konsep Desain Personalisasi
}

\author{
Devanny Gumulya, Winston Jauri \\ Program Studi Desain Produk Universitas Pelita Harapan \\ E-Mail: devanny.gumulya@uph.edu
}

\begin{abstract}
Footwear is essential human being to do many activities, such as working and relax activities. Footwear protects our foot from all kinds of objects that can be dangerous. Recently, there is healthy lifestyle trend, we can see from the emergence of many health products. One such product is the healthy sandals. However, these healthy sandals have problems such as they don't provide much health effects, but only give prejudice so that consumers want to buy it. In terms of product styling, they are very bad, so the target consumer is very specific, they don't have mass market interest. But there is a design opportunity here.

The solution proposed is to design a sandal with personalized insole, so customers can choose the most comfort insole to solve their foot problems such as flat feet, pain in the metatarsal, heel pain, calluses, and a few other problems. Hopefully with this concept finally health sandal can give healthy effect not just a prejudice. This project is supported by a sandal manufacturer, PT. TBS Design Center.
\end{abstract}

Keywords : Ergonomi, Consumer Goods, Health and Lifestyle

\begin{abstract}
ABSTRAK
Alas kaki adalah produk yang sangat diperlukan manusia untuk berjalan. Alas kaki dipakai untuk keperluan sehari-hari pada saat kita bekerja ataupun bersantai. Alas kaki
\end{abstract}

melindungi kita dari segala macam bendabenda yang ada di permukaan tanah yang terdiri dari benda-benda tajam dan berbahaya.

Saat ini tren hidup sehat sedang marak, dapat dilihat dari bermunculannnya produkproduk kesehatan. Salah satu produk tersebut adalah sandal kesehatan. Namun sandal kesehatan yang ada saat ini memiliki banyak masalah : sandal ini tidak memberikan efek kesehatan, tetapi hanya memberikan sugesti sehingga konsumen ingin membelinya. Disisi lain, dari segi estetik tampilannya sangat tidak menarik, sehingga target konsumen juga sangat spesifik hanya orang yang memiliki keluhan, padahal sandal kesehatan sangat baik efeknya bila dipakai sehari - hari. Jadi ada peluang desain disini.

Di paper ini diusulkan perancangan sandal kesehatan dengan konsep personalisasi, sehingga konsumen dapat memilih sol sepatu yang paling nyaman untuk kakinya dan sesuai dengan keluhan kakinya seperti kaki rata, nyeri pada metatarsal, nyeri tumit, kapalan, dan beberapa masalah lainnya. Diharapkan akhirnya sandal kesehatan memang benar dapat memberikan efek sehat bukan hanya sugesti. Projek ini disponspori oleh PT. TBS Design Center.

Kata Kunci : Ergonomi, Consumer Goods, Gaya Hidup dan Kesehatan

\section{Relevansi pada Ilmu Desain Produk:}

Metode penyelesaian masalah secara ilmu desain produk yang dibahas di paper ini dapat 
menjadi salah satu metode untuk menyelesaikan masalah kenyamanan dan desain yang ada pada sandal kesehatan saat ini

\section{Pendahuluan}

Alas kaki merupakan objek yang sangat diperlukan manusia dalam melakukan aktivitasnya, yang dibutuhkan bukan hanya untuk membantunya bermobilisasi tapi juga melindungi kaki dari objek - objek yang dapat melukai telapak kaki. Alas kaki yang ada saat ini terdiri dari berbagai macam jenis ada sepatu, sandal, sepatu sandal, dan berbagai jenis lainnya yang terus berkembang dari masa ke masa dari segi bahan, bentuk, fungsi, teknik produksi yang semuanya ini dilakukan demi meningkatkan kenyamanan. Teknologi yang ada sekarang ini lebih diterapkan pada sepatu olahraga dimana setiap teknik produksi dan bahan saling berkolaborasi sedemikian rupa agar sepatu olahraga tersebut dapat membuat para pemakai merasa nyaman, lebih mudah untuk melakukan gerakan-gerakan, ataupun suatu spesialisasi pada sepatu untuk olahraga tertentu. Untuk selanjutnya alas kaki yang dibahas lebih lanjut adalah sandal.

Permasalahan pada telapak kaki seperti kaki rata, kaki berlengkung tinggi ataupun masalah kaki lainnya seperti kapalan seringkali dikeluhkan. Menurut seorang dokter ahli tulang dan ortopedi masalah terbanyak adalah masalah kaki rata dan kapalan yang terjadi akibat faktor genetis maupun non genetis. Keluhan pada kaki ini sebagian besar disebabkan karena kesalahan pemakaian dan sandal yang ada dipasaran saat ini memiliki kenyamanan yang sangat minim dikarenakan mereka hanya memikirkan dari sisi estetik saja. Selain masalah kenyamanan ada faktor - faktor lainnya yang memperburuk seperti pemakai tidak mengetahui sandal yang sesuai dengan kontur kakinya dan tidak ingin tahu. Produsen sandal kurang memberikan informasi.

Saat ini di pasaran sudah beredar banyak variasi sandal kesehatan, namun pada umumnya mereka hanya memberikan sensasi namun manfaat kesehatan yang sebenarnya tidak pernah terbukti. Dari segi desain, bentuk sandal hanya cocok untuk beberapa segmen pasar. Hal ini yang juga menyebabkan banyak orang enggan untuk menggunakan sandal kesehatan dalam aktivitas sehari - harinya. Tema riset ini disponsori oleh sebuah perusahaan produsen sandal, PT. TBS Dircet Design Center. Perusahaan juga melihat sebuah peluang untuk memproduksi sandal kesehatan dengan konsep baru dari segi kenyamanan maupun desain produk, sehingga dapat menjaring segmen pasar yang lebih besar bukan hanya untuk orang - orang yang memiliki masalah pada kaki. Penulis diberi arahan untuk mendesain sandal yang termasuk dalam salah satu katagori produk PT. TBS Direct Design Center.

\section{Analisa Anatomi Kaki}

Anatomi kaki dibagi ke dalam tiga bagian yaitu hindfoot, midfoot, dan kaki depan:

a. Hindfoot : Bagian belakang kaki yang terdiri dari tulang pergelangan kaki dan tulang tumit. Dua tulang panjang kaki bawah, tibia, dan fibula, dihubungkan ke bagian atas tulang talus untuk membentuk bagian belakang.

b. Midfoot : Bagian tengah kaki yang terdiri darilima tulang tidak teratur yaitu cuboid, navicular, dan tulang cuneiform yang membentuk lengkungan kaki yang berfungsi sebagai shock absorber. Midfoot ini yang terhubung ke belakang dan kaki depan oleh otot-otot disebut plantar 
facia.

c. Kaki depan ini terdiri dari lima tulang proksimal jari-jari yang menyerupai jari-jari tangan. Tulang-tulang jari kaki disebut falang, jempol kaki memiliki dua falang sementara empat lainnya jari-jari kaki memiliki tiga falang. Punggung kaki adalah bagian melengkung dari bagian atas kaki antara jari kaki dan pergelangan kaki.

\section{Kelainan - Kelainan pada Kaki}

Berikut ini akan dibahas beberapa kelainan pada kaki yang kerap ditemui, berdasarkan hasil wawancara dengan dokter Orthopaedic Surgeon dan Medical rehabilitation

\section{Flat Feet}

Bentuk Kelainan kaki yang disebabkan oleh beban yang terlalu berat ataupun kesalahan posisi kaki pada saat didalam kandungan yang menjadikan bentuk kaki menjadirata dan tidak mempunyai lengkungan kaki. Fungsi dari lengkung kaki adalah sebagai penahan guncangan untuk seluruh tubuh kita. Seseorang dengan flat feet akan mempunyai daya tahan untuk berjalan lebih singkat daripada kaki normal, akan terasa sakit berketerusan ke tulang belakang, lutut dan pinggang. Penyebabnya dapat disebabkan oleh faktor genetis: turunan dari orang tua, faktor usia: melemahnya otot dan ligamen yang disebabkan oleh usia lanjut, penyakit neuromuskuler, ataupun faktor lainnya seperti cedera, berdiri untuk jangka waktu yang panjang dengan sepatu yang salah, dan juga seringnya berjalan ditempat yang keras dan datar.

\section{Kapalan}

Kelainan pada telapak kaki menumbuhnya kulit mati mengeras dibawah telapak kaki ataupun dibagian samping ibu jari. Kapalan disebabkan oleh tekanan yang terlampau keras pada kulit dan tulang kaki. Faktor lain yang sering menjadi penyebab kapalan adalah pemakaian alas kaki dengan insole yang terlalu keras, menimbulkan gesekan antara telapak kaki dan insole dan akhirnya kulit menebal dan mengeras. Penderita kapalan akan merasakan rasa sakit bila kita melakukan aktivitas berjalan dan berlari. Untuk mengurangi rasa sakit akibat kapalan, cara yang paling efektif dan termudah adalah dengan penggunaan Orthotics CustomMade (alas kaki yang dibuat berdasarkan kontur kaki pemakai, saat ini dokter spesialis sudah dapat membuat alas kaki khusus) karena nyaman, tahan lama, yang terbuat dari cetakan kaki penderita, dan akan mengurangi rasa sakit yang diakibatkan dari kapalan.

\section{Metatarsalgia}

Kekurangan jaringan lemak pada bagian tulang kaki, dan tekanan yang berlebih pada bagian tumit belakang yang menyebabkan rasa nyeri ketika berjalan akibat tulang menekan ke kulit kaki. Kelainan ini umumnya disebabkan oleh sepatu bertumit tinggi, karena ketika memakai sepatu hak tinggi, tumit terangkat maka berat badan bertumpu pada tulang kaki depan, dengan meningkatnya beban maka jaringan lemak yang menjaga lengkungan tulang meregang, dan hal tersebut memungkinkan satu atau lebih dari 
struktur tulang menurun.

\section{Bunions}

Kelainan pada kaki dimana bagian tulang ibu jari kaki semakin lama membentuk sudut miring. Kelainan ini dapat disebabkan oleh beberapa faktor seperti penggunaan sepatu hak tinggidan sepatu lancip dalam waktu yang lama, karena jenis sepatu ini memberikan tekanan abnormal pada jempol kaki dan menghipit bagian telapak kaki lainya. Faktor lainnya adalah cedera dalam, arthristis, dan beberapa penyakit saraf pada sendi dan jari kaki.

\section{Identifikasi Masalah pada Alas Kaki Sandal Kesehatan}

Observasi Sandal Kesehatan yang umum beredar di pasar.
Kelebihan

a) beberapa sandal kesehatan sudah memiliki kontur insole yang cocok dengan kaki normal maupun kaki flat

b) umumnya sandal kesehatan menggunakan konsep akupuntur yang menekan bagian tertentu pada telapak kaki akan memberikan efek melancarkan peredaran darah maka semua organ tubuh akan menjadi sehat.

Kekurangan
a) material licin
b) tidak memiliki kualitas yang baik
c) desain kurang bervariasi

Kesimpulan dari percobaan dan observasi pengguna lama sandal kesehatan pada beberapa merek sandal kesehatan adalah :

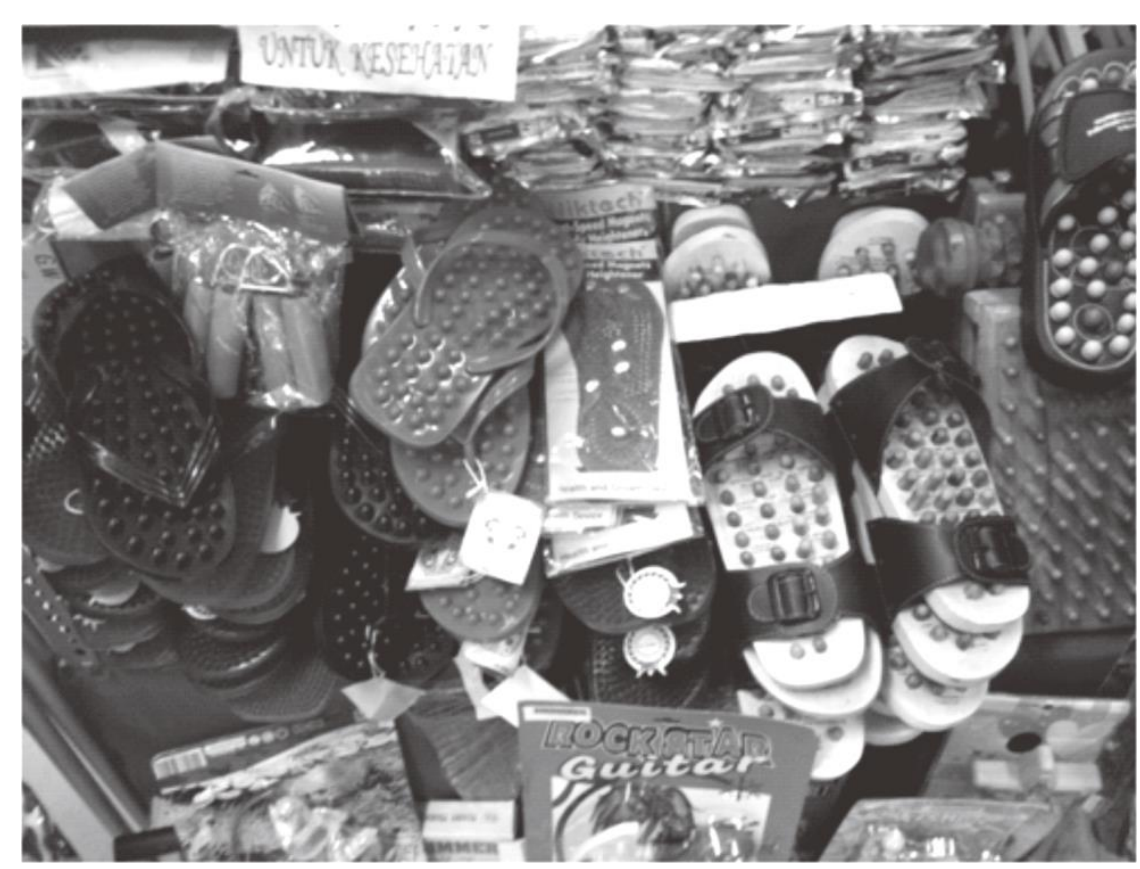

Gambar 1.1 Sandal Kesehatan

(Sumber: Dokumentasi Devany Gumulya) 
a) umumnya sandal kesehatan hanya memberi sensasi saja namun hasil yang terasa hampir tidak ada, tetapi mengakibatkan sakit di telapak kaki.

b) masyarakat awam cenderung mengasosiasikan sandal kesehatan adalah sandal yang memiliki tonjolan-tonjolan

c) hasil konsultasi dengan dokter orthopedic, tonjolan-tonjolan yang ada pada sandal kesehatan umumnya disusun tidak sesuai dengan sarafsarafkaki yang dituju

d) bahan relatif murah dan tidak nyaman untuk dipakai dalam jangka waktu yang lama

e) sandal kurang kuat untuk dipakai sehari-hari

\section{Rumusan Masalah}

Berdasarkan hasil observasi, penulis merumuskan beberapa masalah yang perlu dipecahkan melalui pendekatan ilmu Desain Produk :

1) aspek kenyamanan dan kekuatan bahan, kurang nyaman karena pemilihan bahan yang kurang tepat, misalnya bahan sandal tidak sesuai dengan iklim tropis

2) aspek bentuk dan desain, bentuk sandal kesehatan yang ada saat ini kurang sesuai dengan lifestyle masyarakat yang ada dan hanya menarik bagi segmen tertentu saja. Selain itu desain yang ada saat ini kurang bervariasi dari segi bahan dan warna

3) aspek informasi, masyarakat umumnya tidak mengetahui sandal dengan insole seperti apa yang cocok untuk dirinya dan mereka cenderung tidak tertarik untuk menggunakan sandal kesehatan, oleh karena itu saat ini sandal kesehatan hanya diminati oleh orang tertentu saja.

\section{Konsep Desain Personalisasi}

Melihat minimnya interfensi ilmu desain produk pada sandal kesehatan maka diperlukan inovasi pada produk ini agar dapat mengurangi permasalahan kaki pada umumnya dan produk ini dapat dipakai oleh masyarakat yang lebih luas lagi. Selain itu persepsi masyarakat akan sandal kesehatan dapat menjadi lebih luas lagi, misalnya sandal kesehatan dapat juga dipakai untuk aneka acara, tidak hanya dipakai di rumah.

Perancangan sandal kesehatan ini juga menjadi suatu Lineup terbaru untuk kerjasama dengan PT.TBS Direct Design Center untuk melengkapi lineup CAFU Sensitive, sandal yang menekankan aspek kenyamanan serta kesehatan khusus untuk pria. Selain aspek kenyamanan line up Cafu Sensitif juga memiliki konsep inovasi dari fungsi-fungsi tambahan seperti Add-on atau lepas pasang pada bagian-bagian tertentu memberi sentuhan personal pada setiap produknya dan dapat memberi hasil yang lebih maksimal.

Melihat variasi kontur kaki yang cukup banyak maka konsep personalisasi muncul. Sandal ini didesain dengan konsep personalisasi agar dapat menopang bermacam-macam kontur kaki seperti kaki rata, kapalan dst. Dengan konsep personalisasi ini, diharapkan aspek kenyamanan sandal dapat lebih terpenuhi dan meningkatkan kesehatan kaki. Tidak dari segi ergonomi saja karena perancangan sandal ini juga memfokuskan pada styling, karena pada saat ini kebanyakan sandal kesehatan kurang sesuai dengan lifestyle yang ada. Penyelesaian masalah desain sandal kesehatan ini dibagi menjadi dua yaitu penyelesaian insole dan outsole.

Dari segi bisnis PT. TBS Direct Design Center melihat ada potensi pasar yang sangat besar untuk sandal kesehatan personalisasi ini. 
Perusahaan pun sangat mendukung proses perancangan ini dengan menanggung penuh pembiyaan proses perancangan.

\section{Proses Perancangan}

Untuk proses perancangan penulis membagi per komponen sandal yaitu :

1. Insole : Bagian dalam sandal yang berhubungan langsung dengan telapak kaki, maka proses desain harus menyelesaikan masalah kenyamanan dan kesehatan kaki
2. Outsole : Bagian bawah sandal berhubungan langsung dengan tempat pijakan, maka proses desain harus memperhatikan tektur dan material yang digunakan

3. Uppersole : Bagian atas sandal berhubungan dengan gaya pemakai, maka proses desain harus memperhatikan lifestyle dan selera target pasar.

\begin{tabular}{|c|c|c|c|c|}
\hline \multicolumn{5}{|c|}{ SOLUSI INSOLE UNTUK MACAM-MACAM JENIS KELAINAN KAKI } \\
\hline No. & Jenis Kaki & Bagian Metatarsal (Depan) & $\begin{array}{l}\text { Bagian } A r c \\
\text { (lengkungan telapak kaki) }\end{array}$ & $\begin{array}{l}\text { Bagian } \\
\text { Tumit } \\
\text { Belakang }\end{array}$ \\
\hline 1. & Normal & $\begin{array}{l}\text { Pad dengan kekerasan } \\
\text { sedang dan tidak ada } \\
\text { lengkungan yang menonjol }\end{array}$ & $\begin{array}{l}\text { Dapat berbentuk rata atau } \\
\text { tidak dengan } \\
\text { arcsupport,namun lebih } \\
\text { baik memiliki } \\
\text { kelengkungan walaupun } \\
\text { sedikit dalam batas normal }\end{array}$ & $\begin{array}{l}\text { Pad } \\
\text { menggunakan } \\
\text { kekerasan yang } \\
\text { lebih keras dari } \\
\text { pada bagian } \\
\text { depan namun } \\
\text { tidak terlalu } \\
\text { keras }\end{array}$ \\
\hline 2. & $\begin{array}{l}\text { Flat Feet } \\
\text { dan nyeri } \\
\text { tumit } \\
\text { belakang }\end{array}$ & $\begin{array}{l}\text { Pad menggunakan bahan } \\
\text { dengan kekerasan yang } \\
\text { sangat lembut dan empuk, } \\
\text { Juga menggukanan sedikit } \\
\text { lengkungan yang menonjol }\end{array}$ & $\begin{array}{l}\text { Menggunakan arcsupport } \\
\text { yang lebih tinggi sehingga } \\
\text { dapat membentuk } \\
\text { cekungan pada kaki rata }\end{array}$ & $\begin{array}{l}\text { Pad } \\
\text { menggunakan } \\
\text { kekerasan yang } \\
\text { sama } \\
\text { lembutnya } \\
\text { pada bagian } \\
\text { depan dan } \\
\text { empuk. }\end{array}$ \\
\hline 3. & Kapalan & $\begin{array}{l}\text { Pad menggunakan bahan } \\
\text { yang lebih lembut daripada } \\
\text { kaki normal namun tidak } \\
\text { selembut pada pad untuk } \\
\text { kaki rata. }\end{array}$ & $\begin{array}{l}\text { Menggunakan arcsupport } \\
\text { seperti kaki normal. }\end{array}$ & $\begin{array}{l}\text { Menggunakan } \\
\text { pad dengan } \\
\text { kekerasan lebih } \\
\text { lembut } \\
\text { daripada kaki } \\
\text { normal. }\end{array}$ \\
\hline 4. & $\begin{array}{l}\text { Nyeri pada } \\
\text { telapak }\end{array}$ & $\begin{array}{l}\text { Pad menggunakan bahan } \\
\text { yang sangat lembut dan } \\
\text { kenyal sehingga dapat } \\
\text { menyerap dan menyebarkan } \\
\text { tekanan }\end{array}$ & $\begin{array}{l}\text { Menggunakan arcsupport } \\
\text { seperti kaki normanl tetapi } \\
\text { berbahan lebih empuk } \\
\text { untuk menyerap tekanan }\end{array}$ & $\begin{array}{l}\text { Menggunakan } \\
\text { pad dengan } \\
\text { kekerasan yang } \\
\text { sama seperti } \\
\text { kaki normal. }\end{array}$ \\
\hline
\end{tabular}

Tabel 1.1 Studi Solusi Insole 
Untuk menjawab kebutuhan macam macam kelainan pada kaki yang membutuhkan tingkat kekerasan pad yang berbeda - beda, saat ini sudah beredar silicone insole, pad yang memiliki tingkat kekerasan yang berbeda - beda di tiap bagiannya. Silicone Insole adalah sebuah bagian tambahan yang diletakan di dalam sepatu yang dirancang untuk mengurangi dan mendistribusikan tekanan. Sol ini terbuat dari silikon yang tahan terhadap pertumbuhan bakteri karena diproduksi dengan teknik hypoallergenic tidak beracun dan tidak berbau. Kegunaan sol ini adalah menghilangkan tekanan berulang pada saat berjalan atau berdiri dan menghilangkan rasa yang sangat sakit nyeri tumit, metatarsalgia, arthritis, pad atrofi lemak plantar, dan nyeri punggung dan sendi. Sol ini cocok untuk pemakaian seharihari selama olahraga, melakukan aktivitas bekerja atau kegiatan rekreasi. Sol ini juga anti selip, mudah dibersihkan, dan tahan lama.

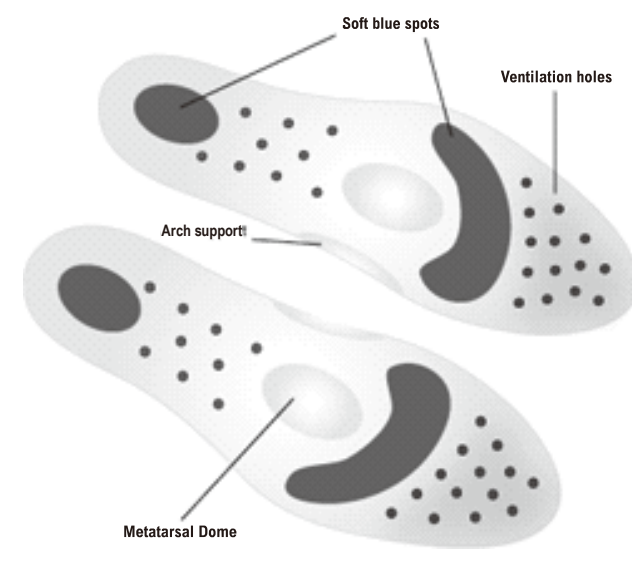

Fitur :

1) tonjolan biru memberikan pijatan lembut pada telapak kaki

2) tonjolan bulat di tengah membantu mengurangi tekanan pada telapak kaki selama dipakai penuh.

3) lubang ventilasi memberikan sirkulasi udara

Pemakaian :

1) umumnya digunakan untuk problem kaki rata

2) deformasi dari metatarsal dan jari kaki yang disebabkan oleh kondisi yang menyakitkan .

3) lelah dan kaki lemah

4) relief dari tumit, lutut dan sakit punggung

5) kaki diabetes

6) deformasi dari struktur tulang kaki dan tumit.

Gambar 1.2 Silicone Insole

(Sumber: Dokumentasi Devany Gumulya) 


\section{Aplikasi pada line up Cafu Sensitif}

Teknologi silicone insole yang memiliki tingkat kekerasan yang berbeda, ini diadaptasi untuk sandal kesehatan yang baru. Insole sandal kesehatan yang baru menggunakan sistem cabut pasang tiga komponen padding yang memiliki tingkat kekerasan dan tekstur yang berbeda - beda untuk kaki normal, flat, kapalan, nyeri telapak. Setiap pad dibuat sesuai dengan kebutuhan kontur dari masing masing kelainan kaki agar manfaat dari sandal kesehatan dapat lebih terasa. Dibawah setiap pad terdapat silinder berkepala seperti baut yang dapat ditekan masuk kedalam insole yang telah dilubangi.
Tiga pad yang dibuat untuk kaki yang memiliki keluhan adalah: refleksiologi untuk keluhan kaki kapalan, flat feet untuk kaki datar dan metatarsal untuk keluhan nyeri pada telapak kaki.
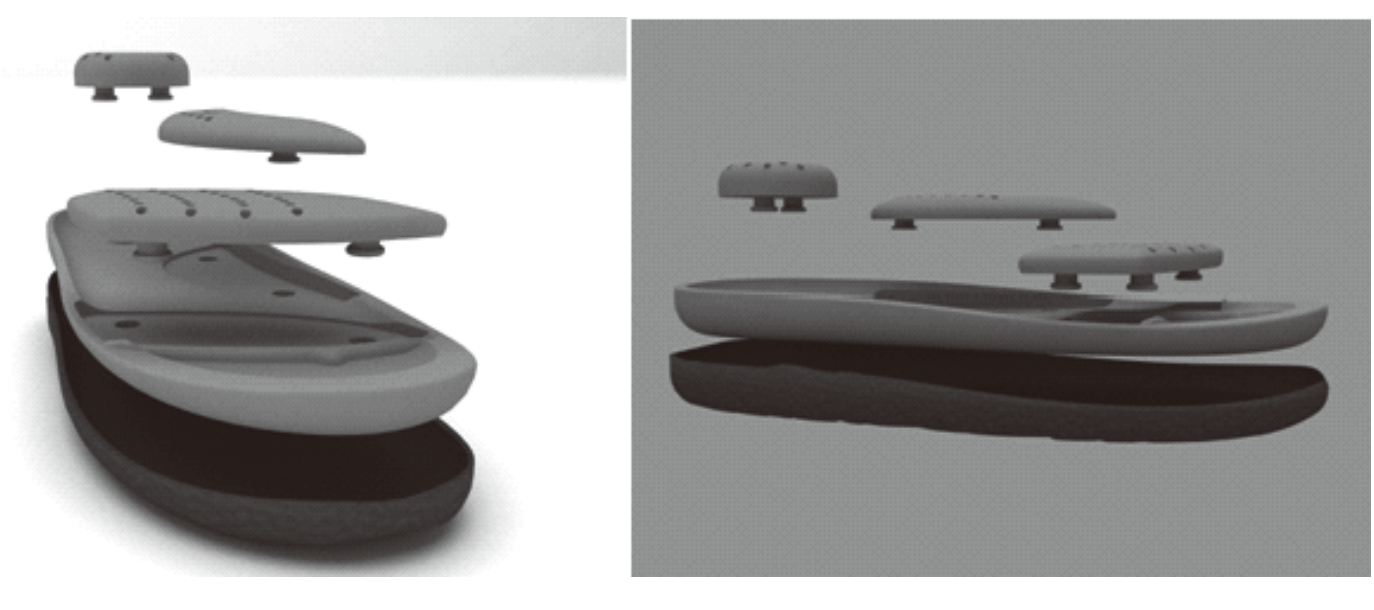

Gambar 1.3 Sistem Padding Insole (Sumber: Dokumentasi Devany Gumulya)

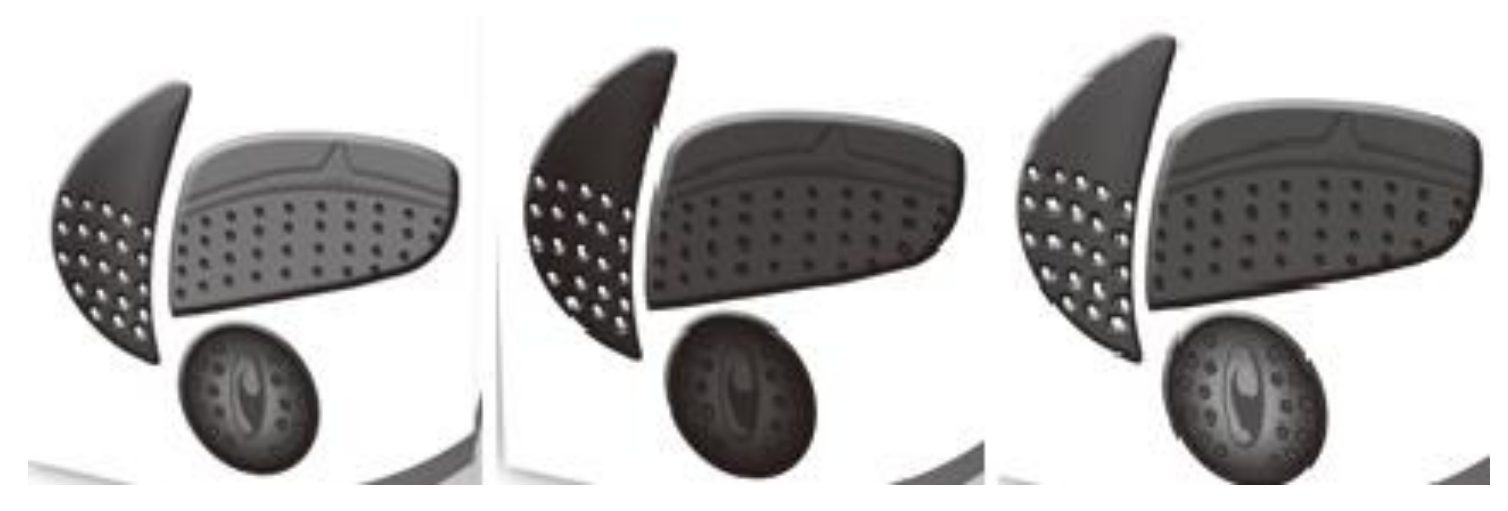

Gambar 1.4 Sandal Pad Refleksiologi, Flat Feet dan Metatarsal (Sumber: Dokumentasi Devany Gumulya) 


\section{Final Desain Insole}

Insole dan pad menggunakan material $P U$ dan juga $E V A$ dikarenakan $P U$ mempunyai sifat yang ringan dan juga tidak berubah bentuk, dan EVA karena sifatnya yang dapat diatur kekerasannya dan juga elastis. Kedua material ini sudah digunakan PT. Tbs untuk memproduksi line up sandal mereka.

\section{b. Perancangan Outsole}

Pencarian styling desain outsole

Outsole menggunakan material solid rubber karena bahannya cukup kuat dan memiliki gaya gesekan yang baik serta harga produksi lebih murah.
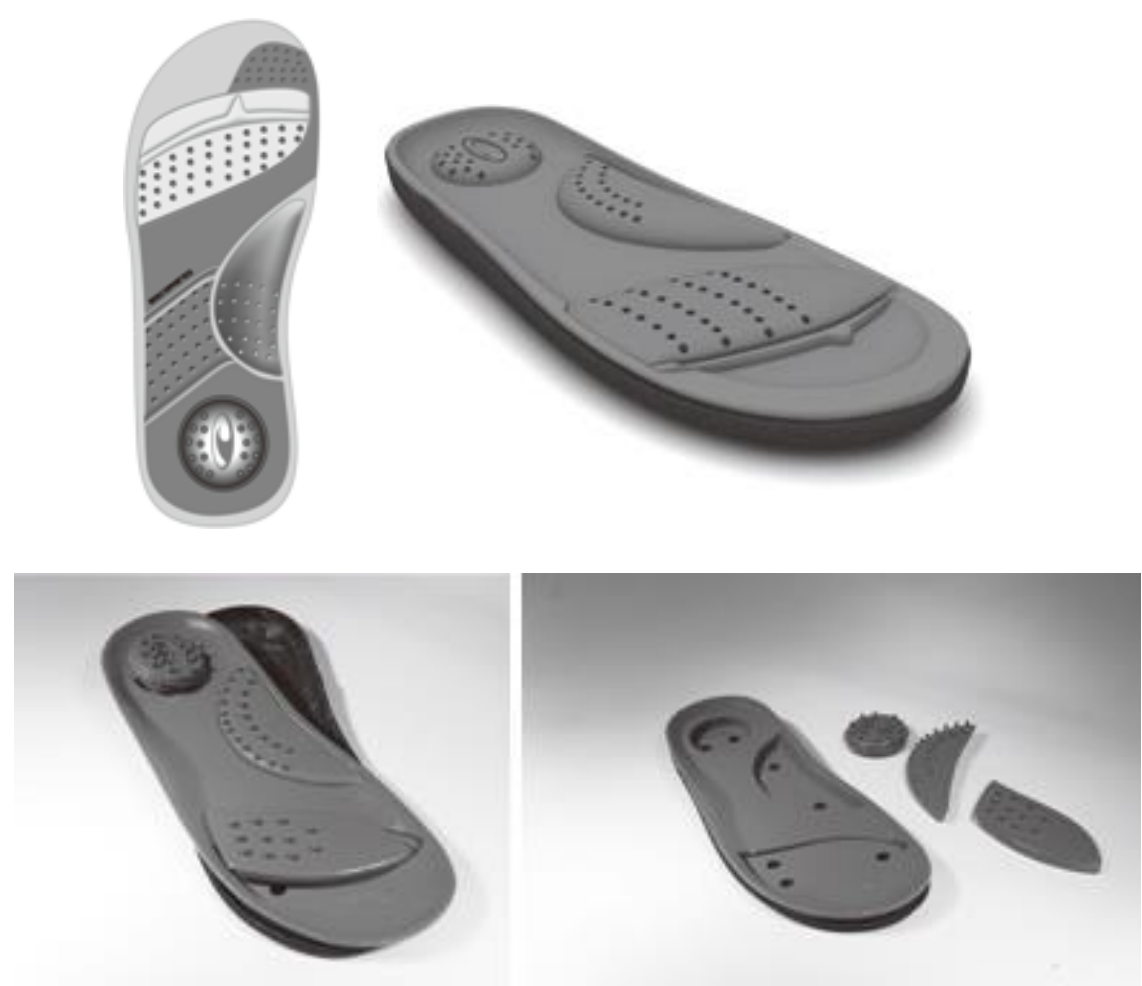

Gambar 1.5 Final Desain Insole

(Sumber: Dokumentasi Devany Gumulya)

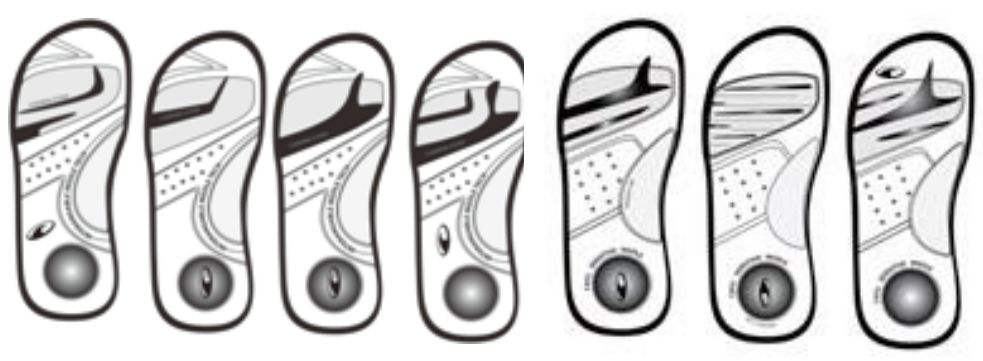

Gambar 1.6 Final Desain Outsole (Sumber: Dokumentasi Devany Gumulya) 


\section{c. Perancangan Uppersole}

Studi lifestyle dan inteprestasi selera pasar

Masalah lain yang dihadapi oleh sandal kesehatan adalah masalah styling uppersole yang tidak sesuai dengan lifestyle pasar yang ada saat ini, hal ini yang menyebabkan segmen pasar sandal kesehatan menjadi sempit. Tiga segmen pasar yang dipilih adalah casual, sporty dan semi formal dengan kalangan ekonomi menengah keatas. Studi moodboard dilakukan untuk lebih memahami karakter dan selera pasar.

\section{1) Gaya Casual}

Profil target pertama yaitu golongan laki-laki memperhatikan pola hidup sehat mulai dari olah raga dan juga makanannya serta meluangkan waktu luang untuk berekreasidan sedikit adventure, namun dia tetap dengan gaya berpakaian yang sangat santai. Target umur dari 25-35 tahun.

\section{Pencarian Styling Desain Sandal Gaya Casual}

\section{2) Gaya Semiformal}

Profil target kedua yaitu golongan lakilaki yang terlihat sudah lebih matang dan berpenghasilan serta selalu ingin terlihat formal tetapi disaat untuk ketempat yang santai dia juga mau terlihat casual. Jadi semi formal merupakan kombinasi antara formal

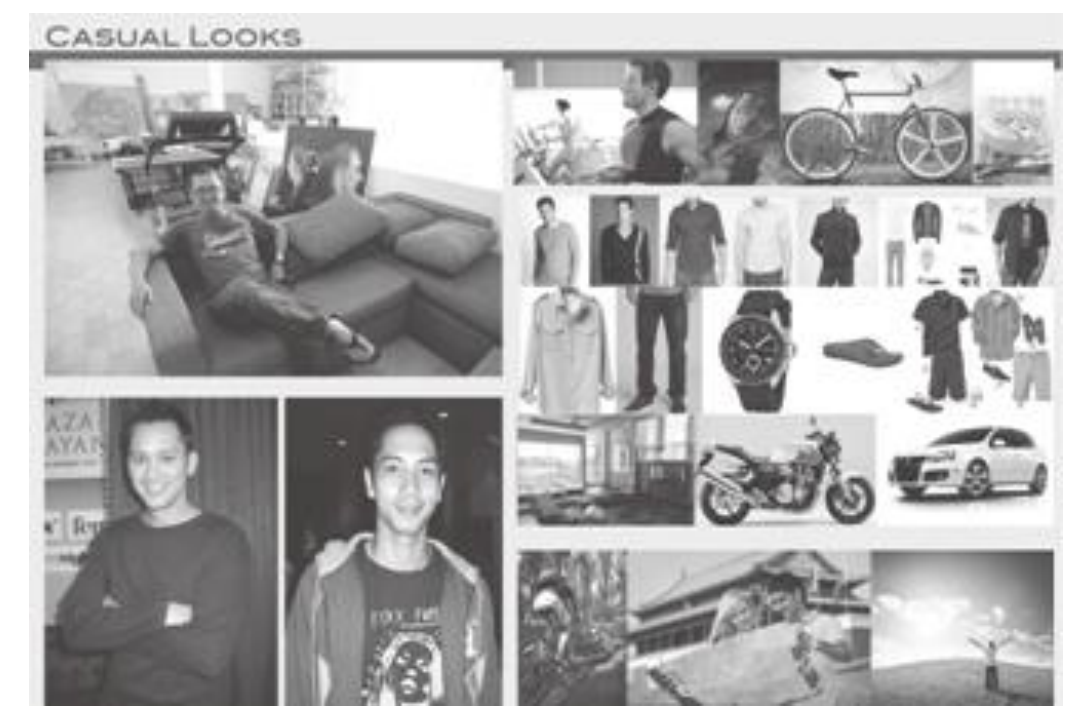

Gambar 1.7 Moodboard Gaya Casual (Sumber: Dokumentasi Devany Gumulya)
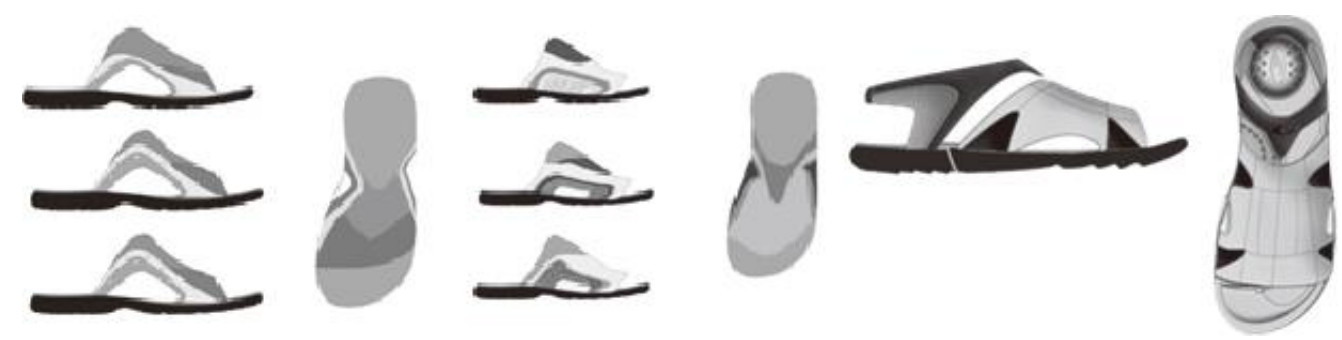

Gambar 1.8 Alternatif Desain Sandal Gaya Casual

(Sumber: Dokumentasi Devany Gumulya) 
dan casual yang dilihat dari padu padan antara kemeja dan jeans yang merupakan dua karakter berbeda dan memiliki beberapa detail-detail yang ditonjolkan dan untuk dari segi warna terlihat dingin namun tetap nyaman dan juga memiliki bentuk-bentuk lama. Target berumur 25-35 tahun.

\section{Pencarian Styling Desain Sandal Gaya Semiformal}

\section{3) Gaya Sporty}

Profil target market ketiga yaitu golongan laki-laki bergaya sporty atau sering dikatakan lebih terlihat sosok kelakilakiannya dimana kesan tersebut dapat ditonjolkan dari bahan bertekstur, warna yang cerah atau highlight dan juga garis-garis yang dinamis. Karena target ini suka pada hal-hal yang memacu adrenalin dan membuat dirinya berbeda dari yang lain. Target umur 25-35 tahun.

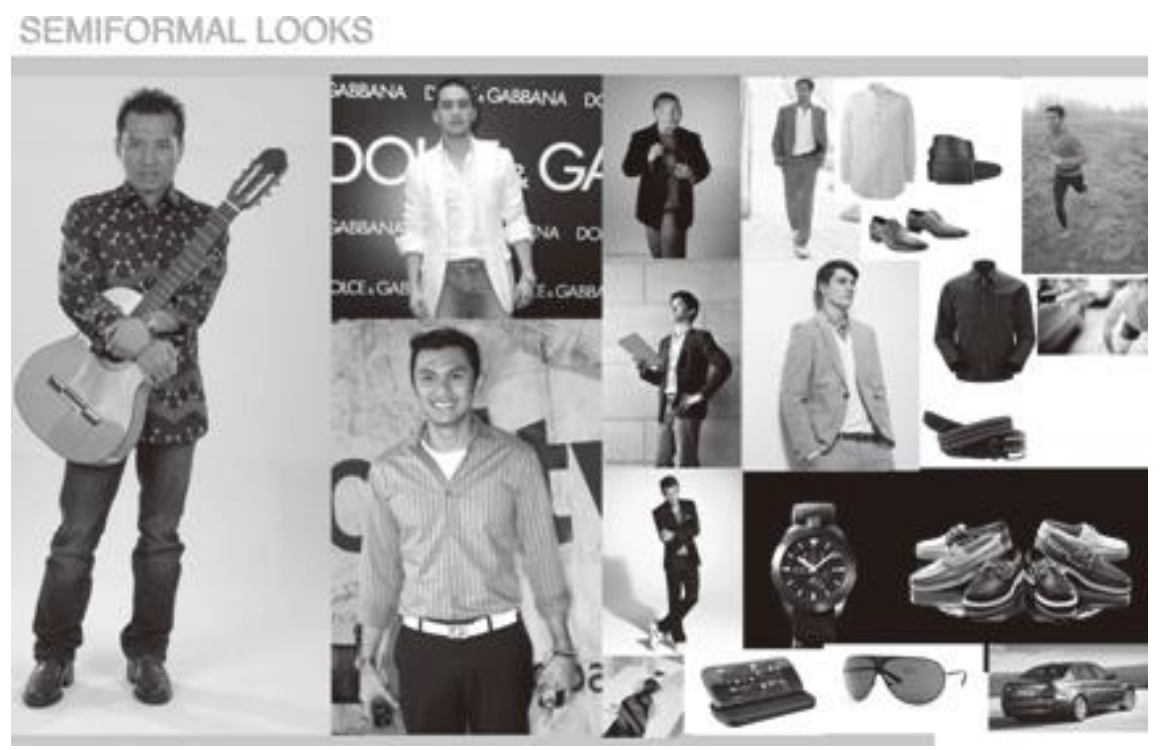

Gambar 1.9 Moodboard Gaya Semiformal

(Sumber: Dokumentasi Devany Gumulya)

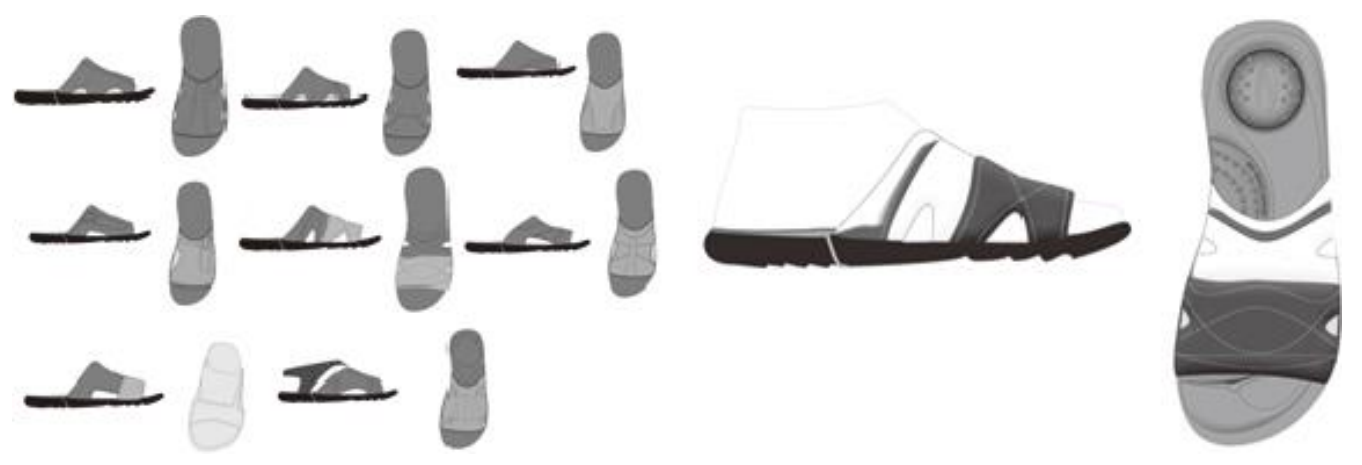

Gambar 1.10 Alternatif Desain Sandal Gaya Semiformal (Sumber: Dokumentasi Devany Gumulya) 


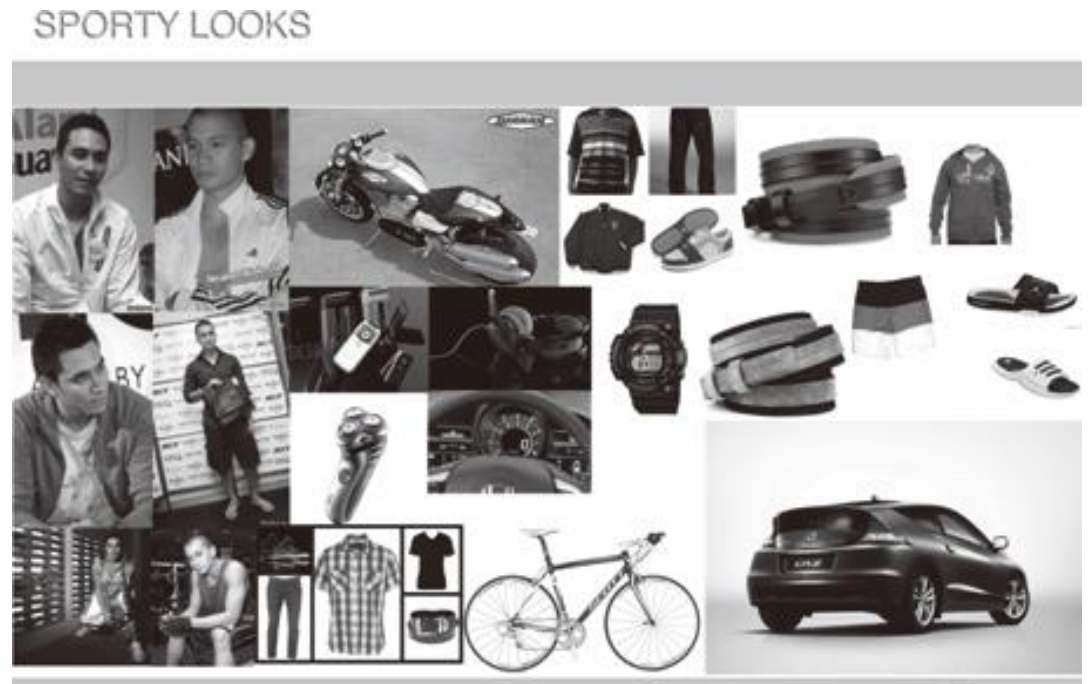

Gambar 1.11 Moodboard Gaya Sporty

(Sumber: Dokumentasi Devany Gumulya)

\section{Pencarian Styling Desain Sandal Gaya Sporty}

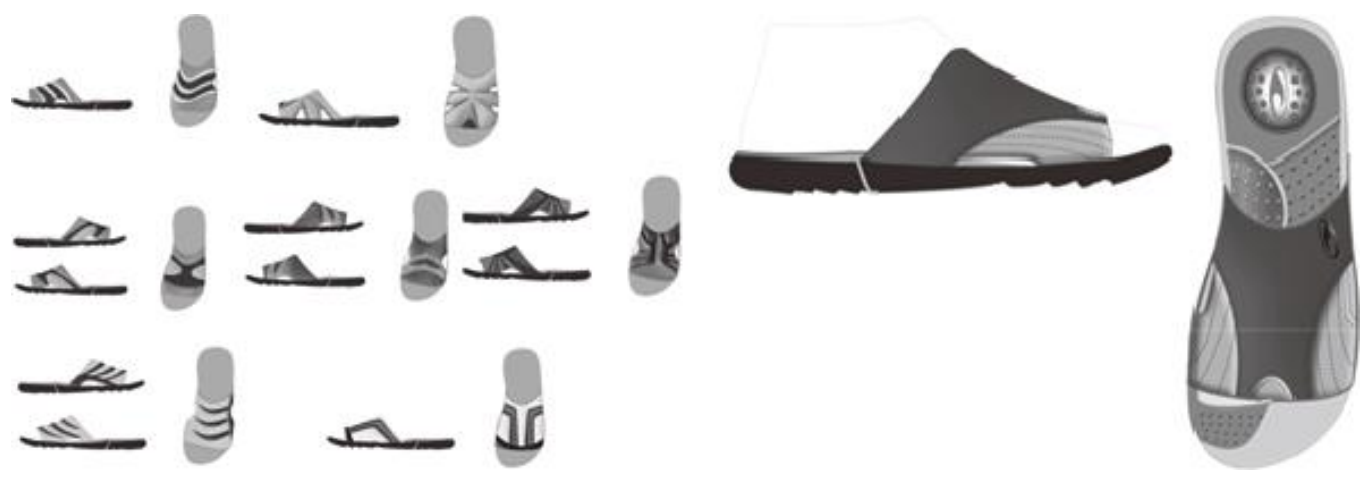

Gambar 1.12 Alternatif Desain Sandal Gaya Sporty

(Sumber: Dokumentasi Devany Gumulya)

\section{Final Desain Uppersole}

Material uppersole menggunakan bahan suede dankulit sintetik pemilihan tersebut dikarenakan bahan kulit sintetik mempunyai daya tahan terhadap iklim tropis dan suede untuk linning bagian dalam dan bagian luar. outsole menggunakan solid rubber karena bahannya campuran harga produksi lebih murah, kuat dan memiliki traksi yang baik.
Foto prototipe belum maksimal, karena belum menggunakan sistem pad yang dimaksud, karena pihak perusahaan harus melakukan beberapa eksperimen terlebih dahulu sebelum memproduksi pad dengan sistem cabut pasang dengan tingkat kekerasan yang berbeda beda. Untuk desain keseluruhan dapat dilihat pada rendering produk. 

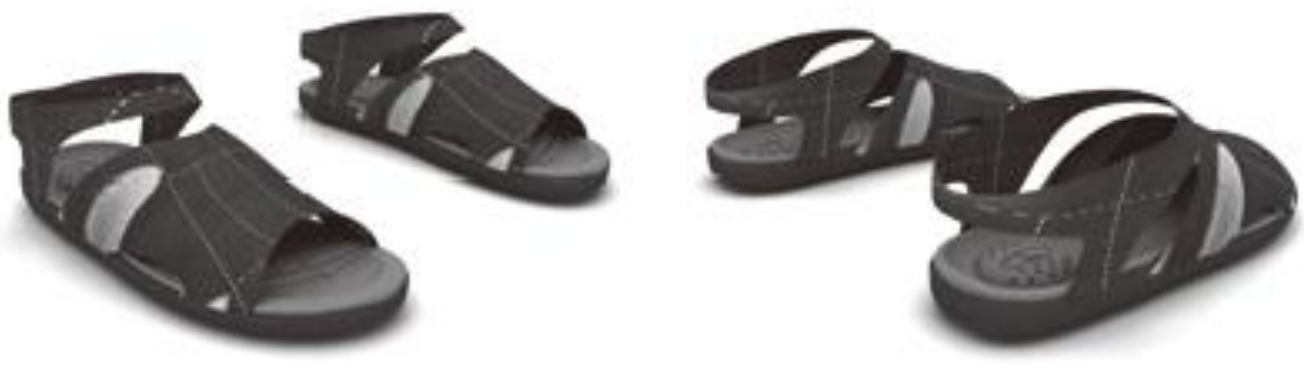

Gambar 1.13 Rendering Final Desain Sandal Gaya Casual (Sumber: Dokumentasi Devany Gumulya)
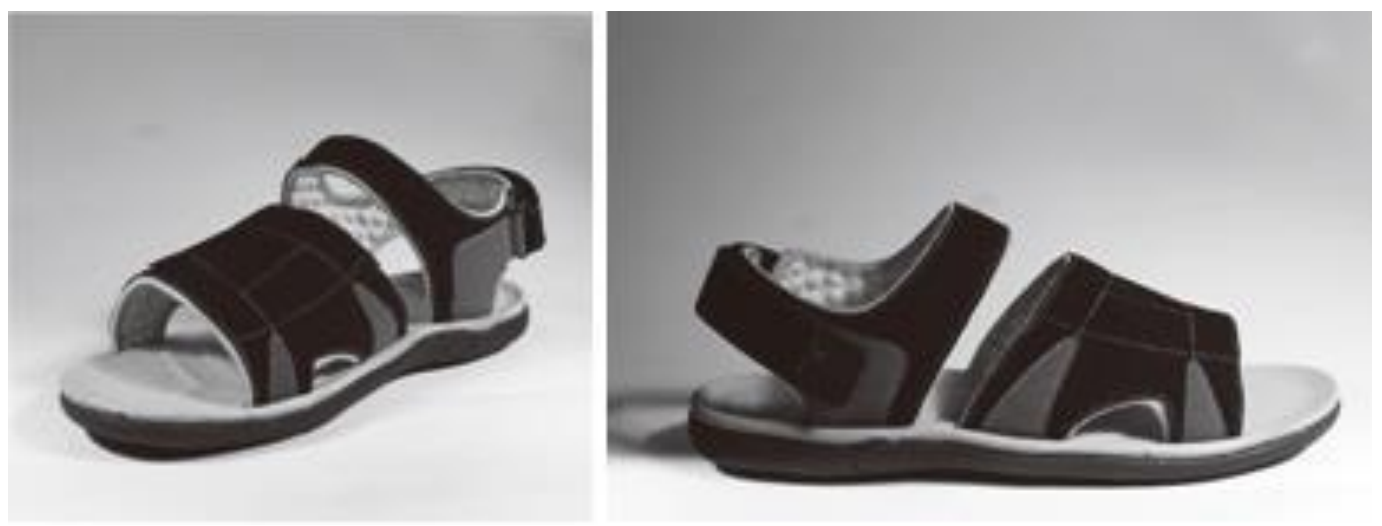

Gambar 1.14 Prototipe Final Desain Sandal Gaya Casual (Sumber: Dokumentasi Devany Gumulya)
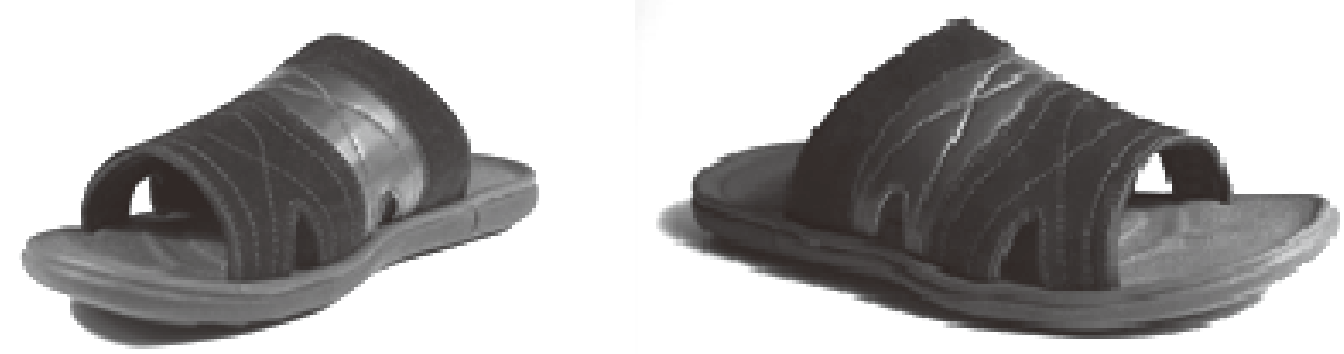

Gambar 1.15 Prototipe Final Desain Sandal Gaya Semiformal (Sumber: Dokumentasi Devany Gumulya)
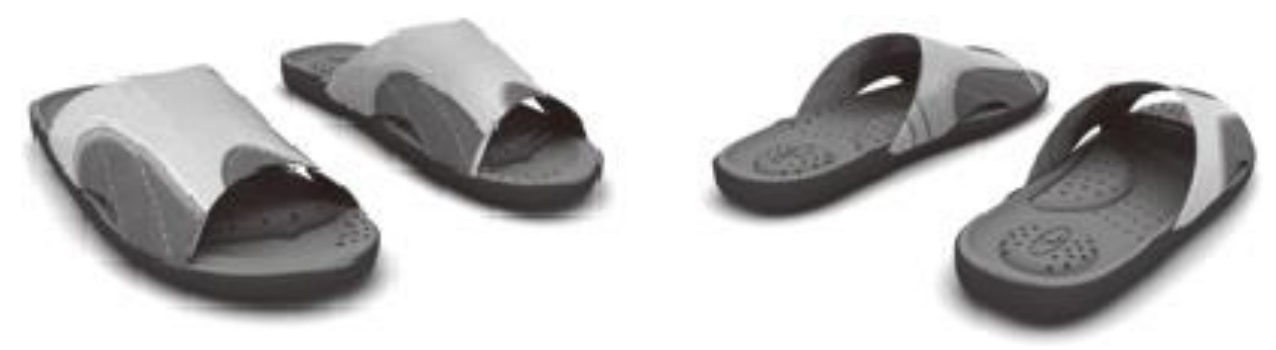

Gambar 1.16 Rendering Final Desain Sandal Gaya Sporty (Sumber: Dokumentasi Devany Gumulya) 

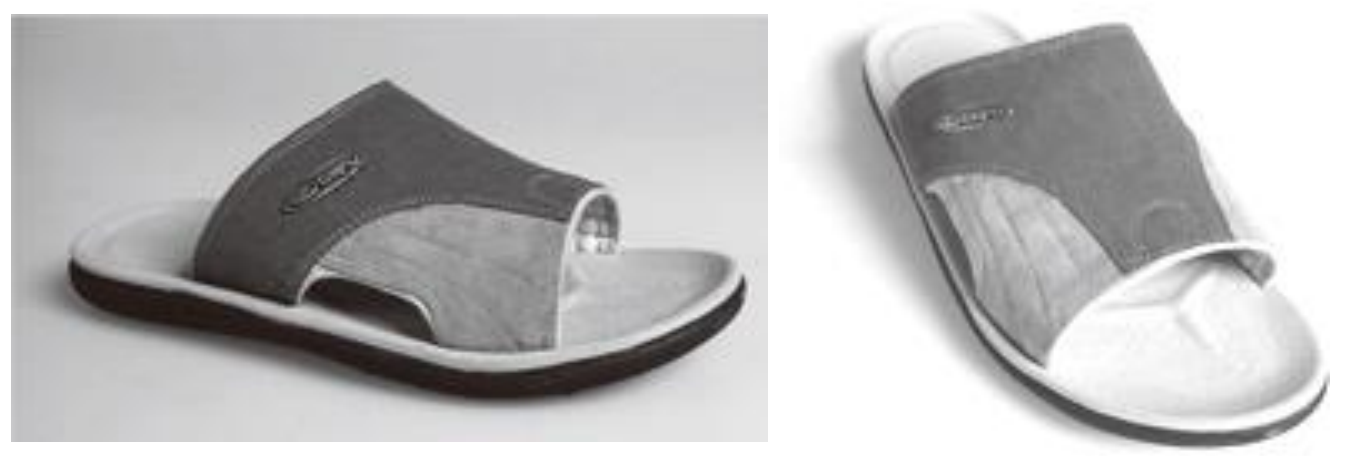

Gambar 1.17 Prototipe Final Desain Sandal Gaya Sporty

(Sumber: Dokumentasi Devany Gumulya)

\section{Kesimpulan}

Usulan perancangan sandal kesehatan ini ditujukan untuk menjawab permasalahan kenyamanan dan bentuk dari sandal kesehatan yang ada saat ini agar pengguna dapat merasa nyaman untuk menggunakan sandal kesehatan dalam segala aktivitasnya. Selain itu dari segi bisnis memperluas segmen pasar sandal kesehatan. Konsep personalisasi merupakan nilai utama dari perancangan, dimana dengan personalisasi pad menjadi nilai lebih dari sandal kesehatan yang ada dipasaran yaitu dari segi desain maupun teknologi. Saran perancang agar dengan adanya sandal ini dapat meningkatkan kesehatan pengguna dan memberikan keleluasaan pengguna untuk melakukan a ktifitas keseharian, dan juga dapat memberikan suatu inovasi kepada industri bahwa sandal kesehatan bukan sandal dengan bontol - bontol yang memberikan rasa tidak nyaman di kaki.

\begin{tabular}{|c|c|}
\hline Fokus Utama Masalah & Solusi Desain \\
\hline $\begin{array}{l}\text { 1. Kurangnya inovasi dalam sandal } \\
\text { kesehatan } \\
\text { 2. Banyaknya masalah pada kaki yang } \\
\text { belum terakomodir dengan sandal } \\
\text { yang ada } \\
\text { 3. Pand angan sandal ke sehat an } \\
\text { dimasyarakat yang salah persepsi } \\
\text { 4. Ku rang n y a e d u k a s i k p a d a } \\
\text { masyakrat sehingga sering terjadinya } \\
\text { kesalahan penggunaan sandal }\end{array}$ & $\begin{array}{l}\text { 1. Memberikan inovasi pada sistem lepas } \\
\text { pasang dan desain yang dapat masuk ke selera } \\
\text { berbagai segmen pasar } \\
\text { 2. Menjawab permasalah dengan pad support } \\
\text { pada beberapa bagian yang dapat disesuaikan } \\
\text { dengan tipe kaki } \\
\text { 3. Memberikan arahan dan pengenalan kepada } \\
\text { masyarakat bahwa sandal kesehatan bukan } \\
\text { hanya untuk orang yang sakit, tapi juga } \\
\text { berguna bagi orang normal } \\
\text { 4. Memberikan penyampaian edukasi dengan } \\
\text { media-media yang menarik }\end{array}$ \\
\hline
\end{tabular}




\section{DAFTAR PUSTAKA}

Byars, MEL. (1999) Sports Wares: Innovations in Design and Material. Rotovision: Mies/East Sussex.

Cliff, Stafford. (2002) 50 Trade Secrets of Great Design Packaging. Gloucester, MA: Rockport

Harkless, Lawrence B. Felder Johnson, Kim. (1998) Foot and Ankle Secrets. Philadelphia: Hanley Belfus

Kunz, Kevin. (1984) The Complete Guide to Foot Reflexology. London: Thorsons

Mader, Sylvia S. (2005) Understanding Human Anatomy and Physiology. New York: Hill

Marieb, Elaine N. (2006) Essentials of Human A n a to my and Phys iology. Sanfransisco, CA: Pearson Benjamin Cumming

Morgan, Conway Lloyd. (1997) Packaging Design. Roto Vision: Miles/East Sussex

Myerson, Mark. (2005) The Good Foot Book. USA. Hunter House

Knight, Sian. (2003) Muscles, Bones, and Skin. London/New York: Mosby

Peacock, John. (2005) Shoes : The Complete Source Book. London: Thames and Hudson

Weimer, Jon. (1993) Handbook of Ergonomic and Human Factors Tables. Upper Sadolle River, NJ: Pretice Hall

NMMDC. Jurnal Kedokteran Olahraga, Akupuntur, Kesehatan. Jakarta. FKUI,2003

Universitas Pelita Harapan. Buku Pengantar Ergonomi Desain 1 dan 2.Karawaci: Jurusan Desain Produk FDTP UPH, 2007
Anonim. Foot. Ourhealth. Available www.ourhealthnetwork.com. Internet; accessed 21 September 2010.

Anonim 1. Perancangan. Kamus Online. Available from www.kamus.net Internet; accessed $10 \mathrm{~S}$ e $\mathrm{p} t \mathrm{e} \mathrm{m} \mathrm{b}$ e r 2010.

Anonim 2. Sandal. Kamus Online. Available from Kamus.net. Internet; accessed 10 September 2010.

Anonim 3. Tent Clasification. American Academy of Podiatric Sports Medicine. Available from w w w . a a p s m.org . Internet; accessed 28 September 2010.

\section{Terima Kasih}

PT. TBS DIRECT DESIGN CENTRE yang telah mensponsori jalannya penelitian ini. 